\title{
Koloneko eta ondesteko minbizia bahetzeko programaren 10. urtea Euskadin
}

\section{0 years of the colorectal cancer screening programme in euskadi}

\author{
Isabel Portillo ${ }^{1}$, Isabel Idigoras ${ }^{1}$, Isabel Bilbao ${ }^{1}$, Eunate Arana-Arri ${ }^{2}$, Luis Bujanda ${ }^{3}$ eta \\ EUSKOLON taldea \\ ${ }^{1}$ Zuzendaritza Nagusia - \\ ${ }^{2}$ Biocruces \\ ${ }^{3}$ Donostialdea ESI/ Biodonostia
}

mariaisabel.portillovillares@osakidetza.eus

\section{Laburpena}

Euskadiko Baheketa Programa 50 eta 69 urte bitarteko biztanleei zuzenduta dago. Gorozkietan ezkutuan dagoen odola detektatzeko testaren (FIT) bidez egiten da, bi urtean behin, eta kasu positiboetan kolonoskopia egiten da sedazioarekin. Metodoa: analisi-kita etxera bidalita gonbidatzen dira indibidualki ikerketako adin-taldeko biztanle oro. Osakidetzako Historia Elektroniko, Minbizi Erregistro eta Heriotza Erregistroko datuak erabiltzen dira informazio-iturri. 2009-2016 bitartean egindako gonbidapen guztien azterketa sexuaren eta adinaren arabera eta biziraupenaren azterketa 2014. urteraino. 2011ko Europako Kalitate Gidan azaltzen diren irizpide eta adierazleak erabiliaz. R eta SPSS aplikazioak erabili dira deskribapen estatistikoa eta biziraute-kurbak (Kaplan-Meyer) lortzeko. Emaitzak: 1.426 .846 baliozko gonbidapen, parte-hartzeak joera positiboa $(p<0,001)$, emakumezkoen parte-hartzea gizonezkoena baino handiagoa, 2016an $\% 74,5$ vs $\% 69,9$. Lesio aurreratuei dagokienez (adenoma aurreratuak eta minbizi inbaditzailea), detekzio-tasa handiagoa da gizonezkoen artean. Kolonoskopiarekiko batez besteko atxikidura \% 95ekoa izan zen; kolonoskopien $\%$ 89,1ean prestakuntza egokia izan zen. 2.856 minbizi-kasuetatik \% 69,2 hasierako estadioetan aurkitu ziren. 377 negatibo faltsu erregistratu ziren, horietatik 85 kasu 69 urtetik gorako pazienteekin. Testaren sentsibilitatea 88,38koa izan zen (\%95eko konfiantza-maila 87,22-89,45 konfiantza-tartean) eta iragarpen-balio negatiboa, berriz, 99,96koa (\% 95eko konfiantza-maila 99,9599,96 konfiantza-tartean). Programak detektatutako kasuen biziraupena 1,3 eta 5 urtetara behaketa-programak detektatu gabeko kasuen edo kasu sintomatikoen biziraupena baino handiagoa izan zen nabarmenki (\% 97,8 vs $\% 87,4$, $\% 93,4$ vs $\% 73,0$ eta $\% 90,1$ vs $\% 66,7$ hurrenez hurren). Ondorioak: Programak balantze positiboa erakusten du, onurei dagokienez; alabaina, beharrezkoa da prozesuaren kalitatean inbertitzen jarraitzea.

Gako-hitzak: Koloneko eta ondesteko minbizia; Baheketa; Test immunokimiko kuantitatiboa; Detekzio goiztiarra; Biziraupena; Kolonoskopia; Kalitatea

\section{Abstract}

The Basque Colorectal Cancer Screening programme is aimed at 50 to 69 year-old citizens. It involves a biennial Faecal Immunochemical quantitative test (FIT) and colonoscopy under sedation as a confirmatory diagnosis in positive cases. Methods: a retrospective cohort study of individuals who were invited to participate by sending the kit to their home. We used the Basque medical record 
Isabel Portillo, Isabel Idigoras, Isabel Bilbao, Eunate Arana-Arri, Luis Bujanda eta EUSKOLON taldea

(Osabide), as well as the Cancer and Mortality registers as information sources. All invitations issued between 2009 and 2016 were analyzed by sex, age and survival till 2014. Criteria and indicators were based on the corresponding 2011 European Guidelines. Descriptive statistical analysis and KaplanMeyer curves. Results: $1,426,846$ valid invitations were evaluated. Positive trends in participation were found $(p<0.001$ ) to be higher in women than men, being $74.5 \%$ vs. $69.9 \%$ respectively in 2016 . Advanced neoplasia (advanced adenomas and invasive cancer) were more frequently detected in men. Colonoscopy compliance after a positive test was 95\%; appropriate cleansing preparation was carried out in $89.1 \%$ of the colonoscopies performed. Out of the 2,856 cancers detected, $69.2 \%$ were found to be initial stage cancers. However 377 cases were registered as false negative cases; of these, 85 cases were older than 69 years. FIT sensitivity was 88.38 (IC95\% 87.22-89.45), with 99.96 (IC 95\% 99.95-99.96) as a negative predictive value. Survival of patients with cancer detected by this programme at 1,3 and 5 years was significantly higher than for patients whose cancers were detected outside this programme or due to symptomatic presentation ( $97.8 \%$ vs. $87.4 \%, 93.4 \%$ vs. 73.0 and $90.1 \%$ vs. $66.7 \%$ respectively). Conclusions: This screening programme has more benefits than disadvantages, but it is clearly necessary to continue investing in the quality of the screening process.

Key words: Colorectal cancer; mass screening; Faecal Immunochemical test; early detection; survival; Colonoscopy; quality

Bidalia: 2018-06-21

Onartua: 2018-11-10

http://doi.org/10.26876/osagaiz.2.2018.174

\section{Sarrera}

Munduko minbiziaren datuen arabera, GLOBOCAN (IARC, OME), 2012an kolon-ondesteko minbizia (KOM) minbizi mota guztien arteko 2.a izan zen maiztasunez emakumezkoen artean, eta gizonezkoen artean. Intzidentziaren datuak aldakorrak dira bai sexuaren arabera bai herrialdearen arabera: kasuen $\% 55$ herrialde garatuetan gertatzen da.

Esaterako, intzidentzia-tasak 10 aldiz handiagoak dira eskualde batzuetan: handienak Australian eta Zeelanda Berrian zenbatesten dira (tasa doitua adinarekiko doitutako 44,8 eta 32,2 kasukoa da 100.000ko gizonezko edo emakumekoetan, hurrenez hurren), eta txikienak, berriz, Mendebaldeko Afrikan (4,5 eta 3,8 kasu $100.000 \mathrm{ko})$.

KOMak eragindako heriotza-tasak txikiak dira (694.000 heriotza, guztizkoaren \% 8,5), eta heriotza gehiago daude garapen eskasagoa duten herrialdeetan. Eskualde horietan, biziraupena baxua da (\% 52). Aldiz, aldakortasuna txikiagoa da munduko heriotza-tasetan (sei bider gizonezkoen artean eta lau bider emakumezkoen artean). Bi sexuetan, erdialdeko eta ekialdeko Europan erregistratzen dira heriotza-tasarik handienak (100.000ko 20,3 gizonezkoetan eta 100.000ko 11,7 emakumezkoetan) eta Afrikako mendebaldean txikienak (3,5 eta 3,0, hurrenez hurren).

Euskadin Minbiziaren Populazio Erregistroa eta Heriotza Tasen Erregistroa dauzkagu, eta baheketaprograma abian jarri arte (2009) intzidentzian gorakadak, heriotza-tasen nolabaiteko egonkortasuna eta biziraupen erlatiboaren hazkuntza ikusi ziren 1986tik 2008ra bitarteko datuak aztertu zirenean².

KOMa bereziki egokia da populazioaren baheketa-programa bat egiteko. Baheketa hauen oinarrian dauden printzipioak Wilson eta Jungner-ek ezarri zituzten lehenbiziko aldiz 1968an, eta 2008an Andermann eta kideek eguneratu zituzten ${ }^{3}$; autonomia-erkidegoetako adostasun-taldeek populazioaren baheketari buruzko esparru-dokumentuan jaso zituzten ${ }^{4}$. 
Hauek dira baheketa egiteko eraginkorrak direla erakutsi duten probak: kolonoskopia, sigmoidoskopia eta gorozkietan ezkutatutako odola - $\mathrm{SOH}-$ (European Guidelines, 20105). Gaixotasunaren historia naturalean KOMa aurretiko polipo batetik abiatu ohi da -polipo guztiak ez dira KOM inbaditzaile bilakatzen (1/10)-. Prozesu hori 10 urte ingurukoa izan daiteke; beraz, lesio aitzindariak eta KOMa garaiz detektatu eta tratatu daitezke.

Polipoek odoljariorako joera dute; gorozkietan ezkutatutako odolaren proba intzidentzia eta heriotza-tasak murrizteko eraginkorra eta kostu-eraginkorra dela frogatu da, eta arrazoizko onargarritasun- eta bideragarritasun-tasak daude hura ezartzeko. Denboraren joanarekin testek eboluzionatu egin dute; hala, test immunokimiko kuantitatiboek (FIT) erakutsitako lesio aurreratuen detekzio-tasa guaiako testena baino handiagoa da eta herritarren artean onarpen handiagoa dute ${ }^{6}$. Merkatuan askotariko testak daude eta batzuetan zaila izaten da haien arteko konparazioa egitea; hala ere, estandarrak ezarri dira eta aukera ematen dute emaitzak alderatzeko, $\mu \mathrm{g}$ hemoglobina/g gorozki unitatearen bidez ${ }^{7}$. 2003an Europako Batzordeak estatu kide guztiei gomendatu zien 50 eta 74 urte bitarteko emakumezkoei eta gizonezkoei $\mathrm{SOH}$ bidez populazio-baheketa bat egiteko ${ }^{8}$.

Duela gutxi, eta minbiziaren aurkako estrategiari jarraikiz (2006 eta 2009), Estatuko Osasun Sistemaren oinarrizko zerbitzu-zorroan 50etik 69 urtera bitarteko emakumezkoei eta gizonezkoei populazioaren baheketa egitea sartu da; horretarako, gorozkietan ezkutatutako odolaren bi urtez behingo testa egingo da eta kolonoskopia bidez egiaztatuko da diagnosia ${ }^{9}$.

Euskadiren kasuan, FIT erabiltzea aukeratu da, eta eskura dauden metodo baliodunak alderatu dira: Sentine ${ }^{\circledR}$ eta OC-Sensor $^{\circledR}$ 2009-2010ean ${ }^{10}$. 2010eko bigarren seihilekotik aurrera, OC-Sensor ${ }^{\circledast}$ erabiltzen da; ebaketa-puntua $20 \mu / g$ gorozki da, hau da, $100 \mathrm{ng} / \mathrm{ml}$ buffer-en baliokidea.

Baheketa honen diagnosi-proba eta urrezko estandarra kolonoskopia optiko osoa da (itsua ere ikusteraino), sedazioarekin. Kolonoskopia horrek konnotazio bereziak ditu; izan ere, diagnosia egiaztatzeko ez ezik, lesio aurreneoplasikoak erauzteko ere balio du, eta horri esker murriztu egin daitezke neoplasia honen intzidentzia eta heriotza-tasak herritarren artean, epe ertain eta luzera.

KOMaren baheketari dagokionez, hainbat azterlanek agerian utzi dute kostu-eraginkortasun handiagoa duela, ezer ez egitearekin alderatuz gero ${ }^{11-12}$.

Gaur egun Euskadiren parte-hartzea duen COLONPREV azterlana ebaluatzen ari dira. Gorozkietan ezkutatutako odolaren testa eta kolonoskopia alderatzen dira, eta oso emaitza itxaropentsuak ari dira lortzen partaidetza- eta detekzio-tasen alderagarritasunari dagokionez. Horiei esker epe ertainera jakin ahal izango dugu zein estrategia den egokiena gure biztanleriarentzat ${ }^{13}$.

Euskadiko programa, Osasun Sailak 2008an onartu zuen Minbiziari buruzko Aholku Kontseiluaren proposamenari esker, 2009an jarri zen abian, 2008an balioztatutako 2003ko Europako gidalerroei jarraiki $^{14}$. Programaren helburua lesio aurregaiztoak eta gaiztoak (adenoma aurreratuak eta minbizi inbaditzailea) garaiz detektatzea eta tratatzea da, intzidentzia eta heriotza-tasak murrizteko.

Azterlan honetan emaitza nagusiak aurkezten dira: parte-hartzea, lesioen detekzioa, KOMaren estadioak, kontrako efektuak, programaren eraginkortasuna eta denbora-horizontea MISCAN-Colon simulazioaren bidez ${ }^{15}$. 
Isabel Portillo, Isabel Idigoras, Isabel Bilbao, Eunate Arana-Arri, Luis Bujanda eta EUSKOLON taldea

\section{Metodologia}

Baheketaren antolaketa:

Baheketaren antolaketak premisa hauek betetzen ditu:

a) Biztanleriaren araberakoa. 50 eta 69 urte bitarteko gizonezkoei eta emakumezkoei zuzendua (598.201 Eustat 2016ren arabera).

b) Bi urtez behin. Test immunokimiko kuantitatiboa (FIT). Eten-puntua: $20 \mu \mathrm{g} \mathrm{Hb} / \mathrm{g}$ gorozki. Lagin bakarra.

c) Lagina bidali egiten da eta testaren emaitza etxean bertan jasotzen da.

d) Kasu positibo guztietan kolonoskopia egiten da sedaziopean.

e) Lehen Mailako Arretaren inplikazioa prozesu osoan.

f) Informazio-sistema interoperatiboa historia klinikoarekin eta datu-base klinikoekin (prozeduren erregistroa, ospitaleko altak, tumoreen ospitale-erregistroak, tumoreen populazio-erregistroak eta hilkortasunaren erregistroak).

g) Zentralizatutako koordinazioa.

h) Prozesuen eta emaitzen kalitate-sistema bat, zeinak aukera emango baitu aurretiaz indarrean dauden Praktika Klinikoen Gidei (PKG) jarraiki ezarri diren adierazleak modu sistematiko eta jarraituan monitorizatzeko eta hobekuntza-neurriak martxan jartzeko.

Gonbidapen-metodoa, gutunak eta protokoloak Osakidetzaren webgunean daude jasota euskaraz eta gaztelaniaz ${ }^{16}$. 1. irudian gonbidapenerako eta jarraipenerako metodo orokorra ikus daiteke.

\section{1. irudia. Baheketaren eta jarraipen-prozesuaren metodo orokorra emaitza negatiboko eta positiboko parte-hartzaileekin}

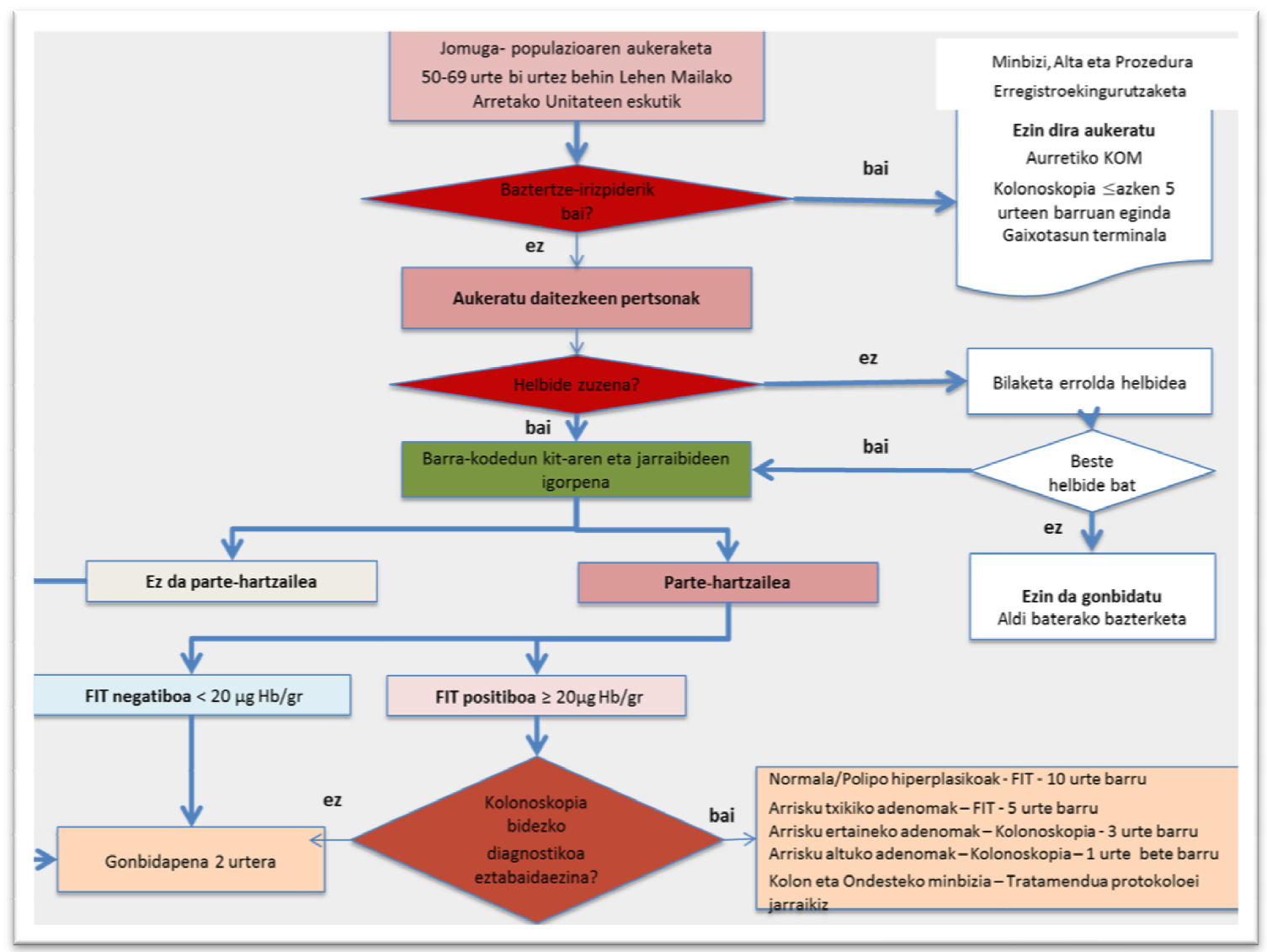


Prozesuaren adierazleak eta emaitzak bat datoz PKG eta Minbiziaren Baheketa Sarearekin ${ }^{17}$.

1. Estaldura: programak gonbidatutako jomuga-populazioa.

2. Herritar aukeragarriak: gonbidapenaren unean inolako baztertze-irizpiderik betetzen ez duen jomuga-populazioa (KOMa, kolonoskopia $\leq 5$ urte, kolektomia osoa, gaixotasun terminala, beste batzuk).

3. Baliozko gonbidapenak: helbide zuzena duten gonbidapenak.

4. Parte-hartzea: kit-a Osasun-zentroan entregatu duten pertsonak eta baliozko emaitza dutenak (positiboa/negatiboa).

5. Positibotasuna: testaren emaitza $\geq 20 \mu \mathrm{g} \mathrm{Hb} / \mathrm{g}$ gorozki ( $\geq 100 \mathrm{ng} \mathrm{Hb} / \mathrm{ml}$ buffer-en baliokidea).

6. Behin betiko diagnostikoko kolonoskopia: testean emaitza positiboa izan duten pertsonak eta kolonoskopia bidez diagnostikoa egiaztatu zaienak (behin betiko emaitza).

7. Kolonoskopia osoa: heste itsuraino iristen den kolonoskopia.

8. Koloneko mukosaren prestaketa egokia: Bostonen eskala $\geq 6$ puntu.

9. Kolonoskopiaren emaitza: a) normala; b) polipo hiperplasikoak; c) arrisku txikiko adenomak (1-2 adenoma eta/edo < $10 \mathrm{~mm}$ eta/edo gradu baxuko displasia); d) arrisku ertaineko adenomak ( $>3$ adenoma eta $<5$ eta/edo $\geq 10 \mathrm{~mm}$ eta $<20 \mathrm{~mm}$ eta/edo osagai bilotsua eta/edo gradu altuko displasia); e) arrisku handiko adenomak ( $>5$ adenoma eta/edo $\geq 20 \mathrm{~mm}$ ); f) KOMa (kasu guztiak $\geq$ pT1); beste patologia aipagarri bat (hesteetako gaixotasun inflamatorioa).

10. Konplikazioak 0-30 egunen barruan: beheko odoljario digestiboa, zulaketa, polipektomia osteko sindromea, sedazio ostekoa, beste batzuk.

11. Detektatutako eta detektatu gabeko minbiziak: FIT emaitza positibo baten ondoren kolonoskopia bidez detektatutako KOMa, eta FIT emaitza negatibo baten ondoren sintomatologia bidez detektatutako KOMa (bitarteko minbizia).

12. Minbizien estadioa: AJCC (I-V)-ri jarraikiz ${ }^{18}$.

Datuen iturriak: Baheketa Programa, Historia Klinikoa (Osabide Global), Ospitaleko Altak, Minbiziaren Ospitaleko Erregistroa eta Minbiziaren Populazio Erregistroa, Hilkortasunaren Erregistroa , Eustat, INDEF.

Programa 2008an onartu zenetik izandako hedapena ezagutzeko 2009-2017tik egindako gonbidapen guztiak aztertu ziren. Gainerako adierazleak lortzeko 2016ra arte egindako gonbidapenen datuak aztertu ziren, KOMen diagnosi bidezko egiaztapen- eta jarraipen-prozesu guztiak amaitutzat eman baitziren. Adin-taldeen eta sexuaren araberako datuak aztertzeko (2009-2014) SPSS v23.0 eta R programen bidez estatistika hauek erabili ziren: khi karratua, joera tenporalak, $2 \times 2$ taula eta KaplanMeyer kurbak. Bestalde, MISCAN-Colon tresna erabili zen intzidentziaren eta heriotza-tasen joerak behatzeko.

\section{Emaitza nagusiak}

2014rako eskualde guztietan behin lehen gonbidapen-oldea bidali ondoren aztertu da. Programaren estaldura lehen gonbidapenean 2014. urtearen hasieran lortu zen; hori bai, hedapena ez da berdina izan Erakunde Sanitario Integratu-guztietan; programak 50-69 urte bitarteko populazioari zuzenduta bi urtez behingo gonbidapenak egiten jarraitzen du; 2017aren amaieran \% 100, \% 90 eta \% 47ko estaldura lortu zen bigarren, hirugarren eta laugarren gonbidapenetan, hurrenez hurren.

Egindako 1.426.846 baliozko gonbidapenetatik parte-hartzea nabarmen igo da 2009tik. Emakumeen parte-hartzea gizonena baino handiagoa da $(p<0,001) 1$. grafikoan ikusten den bezala. 
1. grafikoa. 2009-2016 Parte-hartze tasak

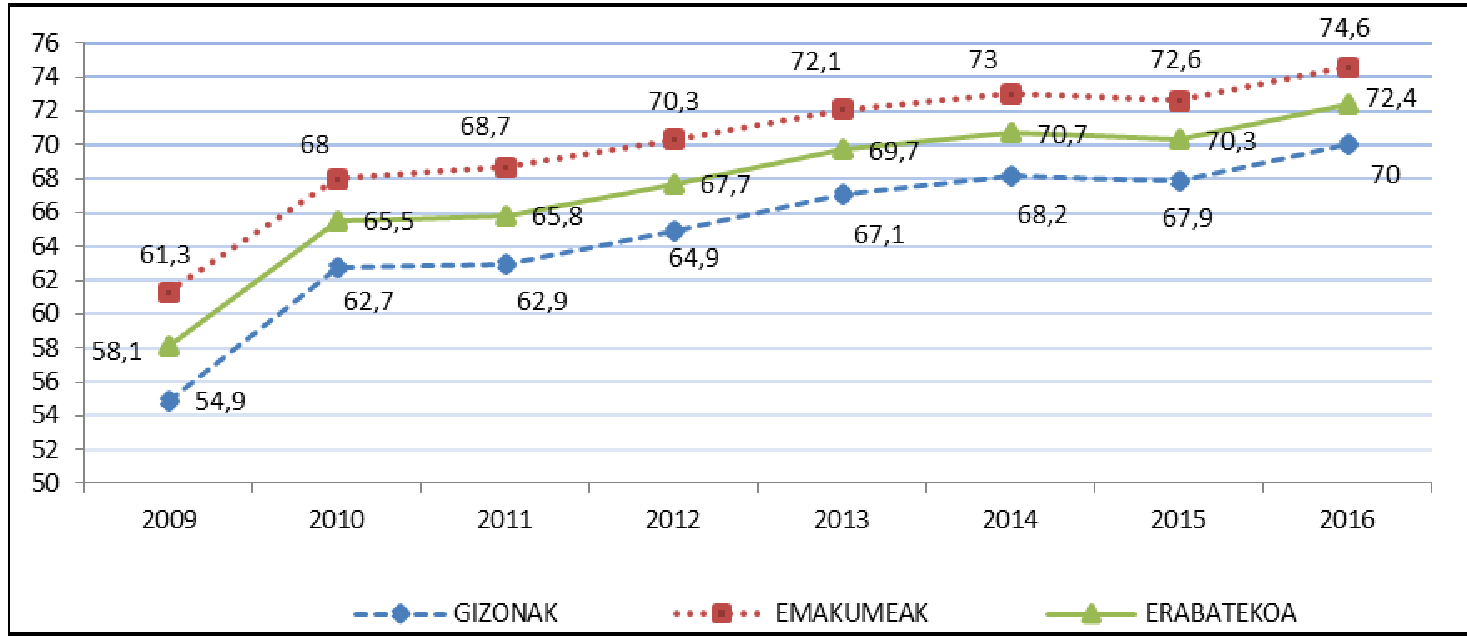

58.330 emaitza positiboetatik kolonoskopiarekiko \% 95eko atxikidura erregistratu zen, eta egindako kolonoskopien \% 93an (54.236) emaitza behin betikoa izan zen. Kolonoskopia osoen tasa \% 98,8tik gorakoa izan zen; hori bai, kolon-prestaketa egokiaren tasa \%89,1ekoa izan zen (Boston $\geq 6$ ). Egindako kolonoskopia guztien \% 0,7an konplikazio larriak aurkitu ziren eta ospitaleratzea beharrezkoa izan zen; konplikazio ohikoenak beheko odoljario digestiboa eta zulaketa izan ziren eta tratamendu kirurgiko edo kontserbatzailea behar izan zen. 1. taulan kolonoskopien emaitzak xehatzen dira; gizonen kasuan adenomak eta minbizia duten pertsonen portzentajea handiagoa dela ikusten da $(p<0,001)$.

1. taula. Detektatutako Lesioak. Behin betiko diagnosiaren egindako kolonoskopiak 2009-2016

\begin{tabular}{|c|c|c|c|c|c|c|}
\hline \multirow[b]{2}{*}{ NORMALA/ HIPERPLASIKOAK } & \multicolumn{2}{|c|}{ EMAKUMEAK } & \multicolumn{2}{|c|}{ GIZONAK } & \multicolumn{2}{|c|}{ GUZTIRA } \\
\hline & 10.870 & $\% 48,7$ & 8.638 & $\% 27,1$ & 19.508 & $\% 36,0$ \\
\hline Arrisku txikiko adenomak & 3.729 & $\% 16,7$ & 5.754 & $\% 18,0$ & 9.483 & $\% 17,5$ \\
\hline Arrisku ertaineko adenomak & 3.806 & $\% 17,1$ & 7.913 & $\% 24,8$ & 11.719 & $\% 21,6$ \\
\hline Arrisku handiko adenomak & 2.515 & $\% 11,3$ & 7.256 & $\% 22,7$ & 9.771 & $\% 18,0$ \\
\hline $\begin{array}{l}\text { Koloneko eta ondesteko minbizia } \\
(\geq \mathrm{pT} 1)\end{array}$ & 981 & $\% 4,4$ & 1.875 & $\% 5,9$ & 2.856 & $\% 5,3$ \\
\hline Digestio-patologia garrantzitsua & 318 & $\% 1,4$ & 362 & $\% 1,1$ & 680 & $\% 1,3$ \\
\hline
\end{tabular}

Programak detektatutako KOMen estadioei dagokienez, minbizien \%69,2 estadio goiztiarrean aurkitu ziren (I-II); ez zen aurkitu sexuaren araberako alde handirik estadioetan eta kokalekuan. KOM kasu kirurgia izan zen lehen tratamendu ohikoena $(\% 59,6)$, eta ondoren, baheketako kolonoskopian egindako tratamendu endoskopiko erradikala $(\% 29,8)$.

Test bidez detektatu ez ziren 377 KOM kasu erregistratu ziren; horietatik 85 kasu 69 urtetik gorako pertsonen artean detektatu ziren, alegia, prebentzio-jarduera bertan behera utzia zutenetan. Programan detektatutako kasuetan ez bezala, \% 40 soilik zeuden hasierako I eta II estadioetan. 
2. Taulan FITaren eraginkortasun-datuak erakusten dira; testaren sentsibilitatea $\% 88,38$ koa dela eta iragarpen-balio negatiboa ia \% 100ekoa dela nabarmentzen dute datu horiek.

2. taula. Programaren eraginkortasuna. 2009-2017

\begin{tabular}{|c|c|c|c|c|}
\hline & & \multicolumn{2}{|c|}{ KOMaren diagnostikoa } & \multirow[b]{2}{*}{ Guztira } \\
\hline & & Positiboa & Negatiboa & \\
\hline \multirow{3}{*}{ FIT } & Positiboa & 2.868 & 56.670 & 59.538 \\
\hline & Negatiboa & 377 & 927.492 & 927.869 \\
\hline & Guztira & 3.245 & 984.162 & 987.407 \\
\hline & & & \multicolumn{2}{|c|}{ Konfiantza-tartea \% 95} \\
\hline \multicolumn{2}{|c|}{ Sentsibilitatea } & $\% 88,38$ & \multicolumn{2}{|c|}{$87,22-89,45$} \\
\hline \multicolumn{2}{|c|}{ Espezifikotasuna } & $\% 94,24$ & \multicolumn{2}{|c|}{$94,20-94,29$} \\
\hline \multicolumn{2}{|c|}{ ABP } & $\% 4,82$ & \multicolumn{2}{|c|}{$4,65-4,99$} \\
\hline \multicolumn{2}{|c|}{$A B N$} & $\% 99,96$ & \multicolumn{2}{|c|}{$99,95-99,96$} \\
\hline
\end{tabular}

Bigarren grafikoan programak detektatu ez dituen kasuen (gonbidatu ez direnak, parte hartu ez dutenak, bitarteko minbiziak) eta programak detektatu dituen kasuen arteko konparazioa erakusten da. Azken kasu horietan handiagoa da biziraupena 1, 3 eta 5 urtera.

\section{2. grafikoa eta argibide-taula. Baheketa-programak detektatu ez dituen eta} detektatu dituen KOM kasuen biziraupena (Kaplan-Meyer)

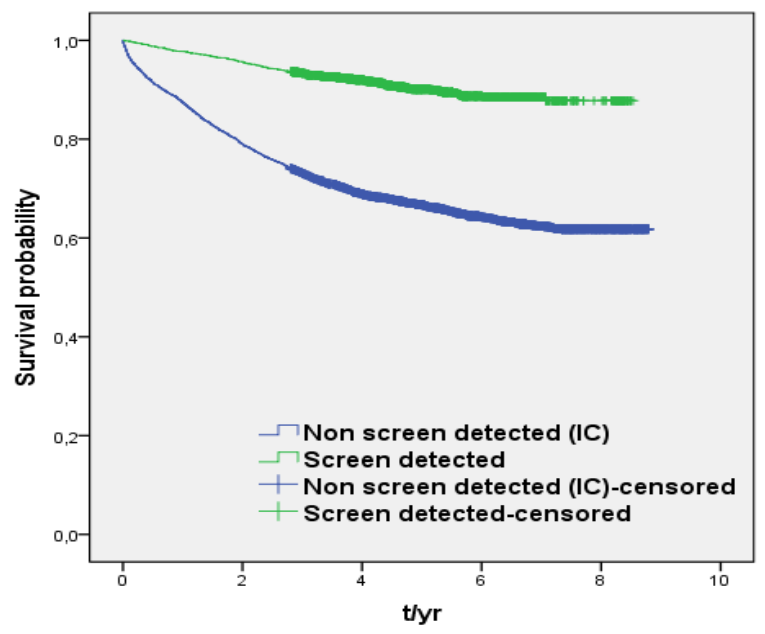

\begin{tabular}{|l|l|l|l|l|} 
& $\begin{array}{l}\text { Biziraupena } \\
1 \text { urte }\end{array}$ & $\begin{array}{l}\text { Biziraupena } \\
3 \text { urte }\end{array}$ & $\begin{array}{l}\text { Biziraupena } \\
5 \text { urte }\end{array}$ & p-Balioa \\
\cline { 1 - 3 } Minbizi sintomatikoa* & $\% 87,4$ & $\% 73,0$ & $\% 66,7$ & $<0,001$ \\
\hline Programak detektatutakoa** & $\% 97,8$ & $\% 93,4$ & $\% 90,1$ & \\
\hline
\end{tabular}

$N^{*}=3.309 ; N^{* *}=2.000$ 


\section{Eztabaida}

Euskadin KOMen Baheketa Programa abian jartzeko estrategia minbiziaren aurkako estrategietan eta Europako Praktika Klinikoko Gidan ${ }^{5}$ jasotako irizpideetan oinarritu da, bai eta CANCON Proiektuan berriki jasotako gomendioetan ere ${ }^{19}$.

Dokumentu horretan gomendioak ematen dira baheketak abiarazi eta ezartzeko; bestalde, aipatzen da beharrezkoa dela programen emaitzak minbiziaren eta hilkortasunaren biztanle-erregistroekin lotzea eta monitorizazioan eta kalitatearen ebaluazioan inbertitzea.

Programaren hedapenari dagokionez, lehen gonbidapenean estaldura osoa lortu duen lehen autonomia-erkidegoa izan gara. 2016an Espainiako Osasun Sistema Nazionalaren estaldura 50-69 urte bitarteko populazioan \% 31koa izan zen ${ }^{17}$. Herrialdekako baheketen egoerari buruzko Europako 2013ko txostenaren arabera, Espainiako autonomia-erkidegoen multzoaren estaldura eta partehartzea batez bestekoaren azpitik egon $\mathrm{da}^{20}$.

Euskadiko programan nabarmentzekoak dira lortutako parte-hartze tasa altua eta goranzko joera; izan ere, 2011tik gainditu egin dira kalitatea bermatzeko Europako PKGren gomendioak (> \% 65). Hala eta guztiz, alde nabarmena antzematen da emakumeen eta gizonen artean; azken horien partehartzeak baxuagoa izaten jarraitzen du, nahiz eta emakumeen kasuan baino askoz handiagoa den lesio aurreratuen eta minbiziaren detekzioa, beste KOM programetan gertatzen den bezala ${ }^{21-22}$. Ebidentzia zientifikoek erakusten dutenez, parte-hartzea hobetu egiten da etxera informazio-gutunak eta kitak bidalita ${ }^{23-24}$. Euskadiko programan, prozesu osoan zehar handia izan da Lehen Mailako Arretako profesionalen parte-hartzea, horrek partaidetzan eragina izan dezakeela ikusi da; hori delaeta, oraindik argitaratzeke dagoen azterketa sakon bat egin behar izan da; izan ere, bibliografian ebidentzia gutxi dago oraindik ${ }^{25}$.

Kontuan izan behar da, halaber, zer faktore sozioekonomiko dauden lotuta parte-hartzearekin. Horrek, aurreko kasuan bezala, azterketa sakonagoa eskatzen du; izan ere, lehen azterketetan zera ikusi zen, estutasun/maila sozioekonomikoari eta sexuari lotutako aldakortasun bat zegoela; hala, profil sozioekonomiko baxueneko gizonek parte-hartze tasa txikienak eta lesio aurreratu eta minbizitasa handienak zituzten ${ }^{26,}$, Erresuma Batuan argitaratutako azterlanei jarraikiz ${ }^{27}$.

Diagnosia egiaztatzeko probari dagokionez (kolonoskopia), atxikimendu handia ikusi da; hori bai, prestaketa egokiaren eta konplikazioen tasa Europako gomendioei jarraikiz monitorizatu eta hobetu beharreko parametroak dira.

Programaren eraginkortasunak eta epe ertain eta luzerako eraginak erakusten dute abian jartzeko estrategia emaitza onargarriak ekartzen ari dela onurei dagokienez; hori bai, beharrezkoa da ikertzen jarraitzea probaren sentsibilitatea eta espezifikotasuna hobetzeko; izan ere, adinaren eta sexuaren arabera FITaren ebaketa-puntua aldatzeari buruzko literatura eskuragarri badago ere, gure kasuan ez litzateke ez eraginkorra ez efizientea izango ${ }^{28}$, eta ez luke bitarteko minbizirik eragotziko. Esan beharra dago, baheketa aurretik KOMen \% 40 soilik detektatzen zirela hasierako estadioetan; baheketan alderantziz gertatzen da, eta biziraupena handiagoa da 1, 3 eta 5 urtera. MISCAN-colon eredua aplikatuta, onura eta kostu-eraginkortasunaren azterketak argitaratu dira berriki ${ }^{29-30}$. Hori bai, beharrezkoa da minbiziaren eta hilkortasunaren erregistroekin etengabe monitorizatzea. Gaur egun FIT bidezko baheketak epe ertain eta luzera duen eraginari buruzko ebidentzia gutxi dago oraindik, azken 10 urteetan soilik egin baita. 


\section{Ondorioak eta gomendioak}

Euskadiko KOM baheketa-programaren estrategia eta emaitzak bat datoz Europako gomendioekin eta eskuragarri dauden ebidentziekin. Beharrezkoa da desberdintasunen murrizketan eta eraginkortasunaren hobekuntzan ikertzen jarraitzea ${ }^{31}$. Baheketa-kolonoskopien kalitatea monitorizatu egin behar da kontrako efektuak murrizteko eta prestaketa ezegokitik eratorritako gastuak gutxitzeko. Beharrezkoa da programaren kalitate globalean inbertitzen jarraitzea haren ekitate, eraginkortasun eta efizientzia bermatzea ahalbidetzen duten azterketen bidez.

\section{Bibliografia}

1. Ferlay J, Soerjomataram I, Dikshit R, Eser S, Mathers C, Rebelo M, Parkin DM, Forman D, Bray F. Cancer incidence and mortality worldwide: sources, methods and major patterns in GLOBOCAN 2012. Int J Cancer. 2015 Mar 1;136(5):E359-86.

2. Izarzugaza MI, Martínez R, Audícana $C$, Larrañaga $N$, Hernández $E$, Tobalina $M C$, De La Cruz M, Laviñeta M, Hurtado R, San Sebastián MC, De Miguel AR, Michelena MJ, López de Lacalle J. El cáncer en el País Vasco: Incidencia, Mortalidad, Supervivencia y evolución temporal [Internet]. Vitoria-Gasteiz: Eusko Jaurlaritzaren Argitalpen Zerbitzu Nagusia; 2010 [Kontsulta 2018-09-03] ${ }^{12} 3$ or. Eskuragarr:

http://www.euskadi.eus/contenidos/informacion/registros epidem presentacion/es def/ad juntos/cancer.pdf

3. Andermann A, Blancquaert I, Beauchamp S, Déry V. Revisiting Wilson and Jungner in the genomic age: a review of screening criteria over the past 40 years. Bull World Health Organ. 2008;86(4):317-9.

4. Grupo de trabajo de la Ponencia de Cribado de la Comisión de Salud Pública. Documento marco sobre cribado poblacional [Internet]. Madrid: Ministerio de Sanidad y Política Social; ${ }^{2013]}$ [Kontsulta 2018-09-04] 35 or. Eskuragarri:

http://www.mscbs.gob.es/profesionales/saludPublica/prevPromocion/docs/Cribado poblaci onal.pdf

5. Segnan, N., Patnick, J., Karsa, L., Comisión de las Comunidades Europeas. Dirección General de Sanidad y Protección de los Consumidores, International Agency for Research on Cancer. European guidelines for quality assurance in colorectal cancer screening and diagnosis. Luxembourg: Publications Office of the European Union; 2010. 386 or.

6. van Rossum LG, van Rijn AF, Laheij RJ, van Oijen MG, Fockens P, van Krieken HH, Verbeek AL, Jansen JB, Dekker E. Random comparison of guaiac and immunochemical fecal occult blood tests for colorectal cancer in a screening population. Gastroenterology. 2008;135(1):82-90.

7. Fraser CG, Allison JE, Young GP, Halloran SP, Seaman H. A standard for Faecal Immunochemical TesTs for haemoglobin evaluation reporting (FITTER). Ann Clin Biochem. 2014;51(Pt 2):301-2.

8. Unión Europea. Council Recommendation of 2 December 2003 on cancer screening . Official Journal of the European Union L 327, 2003ko abenduaren 16a, 34-37 or.

9. España. Orden SSI/2065/2014, de 31 de octubre, por la que se modifican los anexos I, II y III del Real Decreto 1030/2006, de 15 de septiembre, por el que se establece la cartera de servicios comunes del Sistema Nacional de Salud y el procedimiento para su actualización. Boletín Oficial del Estado, 6 de noviembre de 2014, núm. 269, 91369-91382 or.

10. Zubero MB, Arana-Arri E, Pijoan JI, Portillo I, Idigoras I, Lopez-Urrutia A, Samper A, Uranga B, Rodriguez $C$, Bujanda L. Population-based colorectal cancer screening: Comparison of two fecal occult blood test. Front Pharmacol 2014 Urt 4; 00175 
Isabel Portillo, Isabel Idigoras, Isabel Bilbao, Eunate Arana-Arri, Luis Bujanda eta EUSKOLON taldea

11. Lansdorp-Vogelaar I, Knudsen AB, Brenner H. Cost-effectiveness of colorectal cancer screening. Epidemiol Rev. 2011;33:88-100.

12. Tran B, Keating CL, Ananda SS, Kosmider S, Jones I, Croxford M, Field KM, Carter RC, Gibbs P. Preliminary analysis of the cost-effectiveness of the National Bowel Cancer Screening Program: demonstrating the potential value of comprehensive real world data. Intern Med J. $2012 ; 42(7): 794-800$.

13. Quintero E, Castells A, Bujanda L, Cubiella J, Salas D, Lanas Á, Andreu M, Carballo F, Morillas JD, Hernández C, Jover R, Montalvo I, Arenas J, Laredo E, Hernández V, Iglesias F, Cid E, Zubizarreta R, Sala T, Ponce M, Andrés M, Teruel G, Peris A, Roncales MP, Polo-Tomás M, Bessa X, Ferrer-Armengou O, Grau J, Serradesanferm A, Ono A, Cruzado J, Pérez-Riquelme F, Alonso-Abreu I, de la Vega-Prieto M, Reyes-Melian JM, Cacho G, Díaz-Tasende J, Herreros-deTejada A, Poves C, Santander C, González-Navarro A; COLONPREV Study Investigators. Colonoscopy versus fecal immunochemical testing in colorectal-cancer screening. $\mathrm{N}$ Engl J Med. 2012 ;366(8):697-706. Erratum in: N Engl J Med. 2016 May 12;374(19):1898.

14. von Karsa L, Anttila A, Ronco G, Ponti A, Malila N, Arbyn M, Segnan N, Castillo-Beltran M, Boniol M, Ferlay J, Hery C, Sauvaget C, Voti L, Autier P. Report on the Implementation of the Council Recommendation on cancer screening [Internet]. Lyon: International Agency for Research on Cancer; 2008 [Kontsulta 2018-09-04]. 136 or. Eskuragarri: http://ec.europa.eu/health/ph determinants/genetics/documents/cancer screening.pdf

15. Loeve F, Boer R, van Oortmarssen GJ, et al. The MISCAN-COLON simulation model for the evaluation of colorectal cancer screening. Comput Biomed Res 1999; 32:13e33.

16. Euskadiko kolon-ondesteetako minbiziaren programa:

http://www.osakidetza.euskadi.eus/contenidos/informacion/deteccion cancer colorrectal/ eu def/adjuntos/PROGRAMA2017 EU v2.pdf

17. Red de Programas de Cribado de Cáncer [Internet]. Eskuragarri: http://www.cribadocancer.es/index.php/cancer-colorrectal

18. American Joint Committee on Cancer (AJCC). American Cancer Society. $7^{\text {th }}$ Edition. 2009. Eskuragarri:

https://cancerstaging.org/references-tools/quickreferences/Documents/ColonMedium.pdf

19. Albreht T, Kiasuwa R, Van den Bulcke (eds). European guide on quality improvement in comprehensive cancer control. Brussels: Scientific Institute of Public Health; 2017. 164 or.

20. Ponti A, Anttila A, Ronco G, Senore C. Cancer Screening in the European Union, Report on the implementation of the Council Recommendation on cancer screening [Internet]. Lyon: International Agency for Research on Cancer; 2017 [Kontsulta 2018-09-04]. 313 or. Eskuragarri:

https://ec.europa.eu/health/sites/health/files/major chronic diseases/docs/2017 cancerscr eening 2ndreportimplementation en.pdf

21. Clarke N, Sharp L, Osborne A, Kearney PM. Comparison of uptake of colorectal cancer screening based on fecal immunochemical testing (FIT) in males and females: a systematic review and meta-analysis. Cancer Epidemiol Biomarkers Prev 2015;24:39-47.

22. Portillo I, Arana-Arri E, Idigoras I, Espinás JA, Pérez-Riquelme F, de la Vega M, González A, Oceja E, Vanaclocha M, Ibáñez J, Salas D, Grupo Cribea. Proyecto CRIBEA, lesiones detectadas en seis programas poblacionales de cribado de cáncer colorrectal en España. Rev Esp Salud Pública 2017; 91(1): e1-e10

23. Camilloni L, Ferroni E, Cendales BJ, Pezzarossi A, Furnari G, Borgia P, Guasticchi G, Giorgi Rossi P; Methods to increase participation Working Group. Methods to increase participation in organised screening programs: a systematic review. BMC Public Health. 2013; 13:464. 
24. Giorgi Rossi P, Grazzini G, Anti M, Baiocchi D, Barca A, Bellardini P, Brezzi S, Camilloni L, Falini $P$, Maccallini V, Mantellini P, Romeo D, Rubeca T, Venditti MA. Direct mailing of faecal occult blood tests for colorectal cancer screening: a randomized population study from Central Italy. J Med Screen. 2011; 18(3):121-7.

25. Hanks H, Veitch PC, Harris MF. A rural/urban comparison of the roles of the general practitioner in colorectal cancer management. Aust J Rural Health. 2008; 16(6):376-82.

26. Hurtado JL, Bacigalupe A, Calvo M, Esnaola S, Mendizabal N, Portillo I, Idigoras I, Millán E, Arana-Arri E. Social inequalities in a population based colorectal cancer screening programme in the Basque Country. BMC Public Health.2015; 15:1021. doi: 10.1186/s12889015-2370-5.

27. von Wagner C, Baio G, Raine R, Snowball J, Morris S, Atkin W, Obichere A, Handley G, Logan RF, Rainbow S, Smith S, Halloran S, Wardle J. Inequalities in participation in an organized national colorectal cancer screening programme: results from the first 2.6 million invitations in England. Int J Epidemiol. 2011; 40(3):712-8. doi: 10.1093/ije/dyr008.

28. Arana-Arri E, Idigoras I, Uranga B, Pérez R, Irurzun A, Gutiérrez-Ibarluzea I, Fraser CG, Portillo I; EUSKOLON Group. Population-based colorectal cancer screening programmes using a faecal immunochemical test: should faecal haemoglobin cut-offs differ by age and sex? BMC Cancer. 2017; 17(1): 577. doi: 10.1186/s12885-017-3555-3.

29. Idigoras I, Arrospide A, Portillo I, Arana-Arri E, Martínez-Indart L, Mar J, de Koning HJ, Lastra R, Soto-Gordoa M, van der Meulen M, Lansdorp-Vogelaar I. Evaluation of the colorectal cancer screening Programme in the Basque Country (Spain) and its effectiveness based on the Miscan-colon model. BMC Public Health. 2017; 18(1):78. doi: 10.1186/s12889-017-46393.

30. Arrospide A, Idigoras I, Mar J, de Koning H, van der Meulen M, Soto-Gordoa M, MartinezLlorente JM, Portillo I, Arana-Arri E, Ibarrondo O, Lansdorp-Vogelaar I. Cost-effectiveness and budget impact analyses of a colorectal cancer screening programme in a high adenoma prevalence scenario using MISCAN-Colon microsimulation model [Internet]. BMC Cancer 2018 [Kontsulta 2018-09-04]; 18(1):464. Eskuragarri: https://doi.org/10.1186/s12885-0184362-1

31. Osasun Sailaren Ildo Estrategikoak- 2017- 2020.

http://www.euskadi.eus/contenidos/informacion/publicaciones departamento/eu def/adju ntos/stp/ildo-estrategikoak.pdf

\section{Euskolon taldea}

José Luis Hurtado, Carmen de No, Aitor Orive, Carlos Enciso, Maite Escalante, José Javier Aguirre, María Begoña Atarés,Baltasar Cermeño, José Antonio Romeo; José Domingo Sardón, Lorans Fernández, Lorea Ibiricu, Maria Udiarraga, Patricia Seoane, Severina Domínguez (Araba ESI); Luis Bujanda, Inés Gil, Ana Irurzun, José Miguel Larzabal, Maddi Garmendia, Yolanda Saralegui, Jose María Enriquez-Navascués, Adelaida Lacasta, Arrate Querejeta, Larraitz Egaña, Unai Goikoetxea; Fernando Mujika, Eva Zapata, Javier Herranz (Donostialdea ESI); Miren Edurne Marañón, Maria Esther Pereda, Aitor de Juan (Debagoiena ESI); José Francisco Egido, Leire Zubiaurre, Juana María Rodriguez (Debabarrena ESI); Esteban San Pedro, Luisa Goyeneche, Jose María Arrinda (Bidasoa ESI); Julio Alfredo Bernuy, Marta Sáiz (Goierri-Urola Garaia ESI); Maria Luz Jauregui (Tolosaldea ESI); María Isabel Rodriguez, Maria Imaz, Francisco Polo, Maria Josefa Ulloa, Angel Calderón, Maria Carmen Etxezarraga, Nagore Arbide, Alberto Loizate, Jesús Maria Gómez, Francisco Javier Fuertes, Nani Pérez, María Victoria Bárcena, Maria José Fernández (Bilbao-Basurto ESI); Cristina Quesada,Marian Puertollano, Gaspar Lantarón, Raquel Pérez, Maria Jesús Suarez, Angel Barturen, Enrique Ojembarrena, César Ibarra, David Coto, Jose Ignacio López Fernández, Maria del Mar Ramirez, José 
Isabel Portillo, Isabel Idigoras, Isabel Bilbao, Eunate Arana-Arri, Luis Bujanda eta EUSKOLON taldea

María García, Marta Santamaría, Iñigo San Miguel, Aurora Lasso, José María Peña, Ricardo Ituarte (Ezkerraldea-Enkarterri ESI); José Ignacio Merino, Eduardo de Miguel, Inmaculada Barredo, Vicente Portugal, Fernando Garicano, Montserrat Mangas, lago Rodriguez (Barrualde-Galdakao ESI); Maria Luz Marqués, Cristian Amezaga, Fidencio Bao, Haritz Cortés (Uribe ESI); Anaiansi Hernández, María Fernández (Barakaldo-Sestao ESI); José Luis Bilbao, Isabel Portillo, Isabel Idigoras, Isabel Bilbao, Eduardo Millán (Zuzendaritza Nagusia); Eunate Arana-Arri, Natale Imaz, Lorea Martínez-Indart, Nere Mendizábal (BioCruces); Arantza López de Munain, Covadonga Audicana, Nerea Muniozguren, Marta de la Cruz, Visitación de Castro, Nerea Larrañaga, Esther Hernández, Iñaki Gutierrez-Ibarluzea, Marta López de Argumedo, Eva Reviriego (Osasun Saila); Saloa Unanue, Amaia Bacigalupe, Unai Martín (EHU) 